\title{
Analysis on the Disclosure Problems of Accounting Information in Charitable Organizations
}

\author{
Jiayi Chen ${ }^{1, *}$ \\ ${ }^{1}$ Nanjing Foreign Language School Xianlin Campus, Nanjing, China, 210000
${ }^{*}$ Corresponding author. Email: jiayi0603@163.com
}

\begin{abstract}
Charity is a very important institution in the public domain. Through donation income, funds are distributed to people in need of help in society. However, according to the theory of public goods, information asymmetry and principal-agent theory, it can be seen that charitable organizations access more information than donors. Accounting statements are the only way for charitable organizations to provide internal information to the society. People's willingness to donate is strongly related to the integrity of accounting statements. When the organization's accounting information improves, credibility and transparency of the organization will also increase, which is also an important aspect of the long-term development of charitable organizations. Through discussing the development and current situation of charitable organizations, charitable organizations have insufficient government supervision, inconsistent accounting systems, low awareness of disclosure and the need for adjustment of internal organizations. This paper puts forward three areas that can be improved: setting up a unified accounting information disclosure system, strengthening government management and improving social disclosure awareness.
\end{abstract}

Keywords: Charity organization, accounting information, information disclosure, accounting.

\section{INTRODUCTION}

Charitable organizations have always been an important intermediary organization for people to donate money to help others. People donate money to charitable organizations, hoping that charitable organizations can do their best to provide the money for people who really in need. Charitable organizations have always played an active role in the public service. However, in recent years, many charitable organizations have failed to perform their due responsibilities, leading to many negative news' generation. As a result, there is collapse of people's trust in charities. The best way for people to understand a charity is the information disclosure of the charity. According to a large number of researches, the accounting disclosure quality of charity organizations is related to people's donation behavior. When the quality of accounting disclosures improves, people tend to donate more. In addition, charitable organizations themselves can use accounting information to understand the internal operations of the organization, thereby helping charitable organizations to make better use of money, make effective decisions and improve the efficiency of charitable organizations. At the same time, external organizations can also objectively evaluate charitable organizations through accounting disclosure information. A unified accounting disclosure system helps the public to objectively evaluate charitable organizations and strengthen public's supervisory role. Therefore, whether it is from the social or economic level, improving the transparency and credibility of information disclosure is an important aspect of the long-term development of the foundation.

According to the dictionary, the charity refers to an organization set up to provide help and raise money for those in need. The purpose of charitable organizations is generally considered to eradicate poverty, promote educational development and other socially beneficial undertakings. According to Chinese law, charitable organizations are social groups or private non-enterprise units, but the important characteristic why charitable organizations do not meeting this definition is public welfare. Donors with social ethics help others through charitable organizations, thereby promoting a more reasonable distribution of social resources.

Charities have the following financial characteristics: First of all, charitable organizations do not aim to increase profits. This indicator can be eliminated in the accounting elements of charitable organizations. 
Secondly, customers are not the main source of funds. Instead of goods trade, the main source of funds for charities is donation income, and the services provided by charities will not change with the amount of donated money. The last point is the assets and interests received belong to charities themselves, and investors do not expect to recover funds or obtain profit.

\section{THEORIES RELATED TO INFORMATION DISCLOSURE}

\subsection{Public goods theory}

The two most important characteristics of public goods are the non-rivalness and non-excludability. Non-rivalness means that an increase in someone's consumption will effect the availability of the good, while the non-excludability means that people cannot prevent other people from consuming the good. The charitable organizations' services belong to the public goods because they need to provide all donation to the whole society. This theory emphasizes that all consumers can consume public goods without paying any price, and the supplier cannot pass on the production cost of public goods to consumers [1].

According to public goods theory, charitable organizations should actively upload detailed financial information so that other people can better know the operation of the organization in order to implement their regulatory rights. In addition, the government should supervise charitable organizations to ensure the progress of activities.

\subsection{Asymmetric information theory}

The asymmetric Information theory means that the information availability between buyers and sellers is unbalance: those with sufficient information are more advantageous, while those with poor information are disadvantageous. Normally, asymmetric information theory suggests that sellers may possess more information than buyers, skewing the price of goods sold. As a result, the theory argues that low-quality and high-quality products can command the same price, given a lack of information on the buyer's side. Under such circumstances, sellers will conceal information that is not good for them based on their own interests, thus causing harm to the interests of buyers. Such behavior results in the party with more information having more advantages to conceal the information and obtain benefits. Moral hazard refers to the deliberate concealment of some relevance about this situation by the person with the information advantage in order to harm the relevant interests of other people. Information [2].

Information asymmetry can also occur in charitable organizations. The main reason is that the donors will not receive any substantive services in the end. As a result, it is impossible for donors to evaluate the organization. In addition, charitable organizations may choose to conceal some data due to reasons such as economic benefits and corruption, so that the public will obtain incomplete and accurate data.

\subsection{Principal-agent theory}

The principal-agent problem is a conflict in priorities between the owner of an asset and the person to whom control of the asset has been delegated. The principal delegates a degree of control and the right to make decisions to the agent. But the principal retains ownership of the assets and the liability for any losses.

There is also such a principal-agent relationship in charitable organizations. Donors provide donations to the charity. Only the charity can control the money [3], while the donor has the right to supervise. Under such special relationships, it is particularly important for charitable organizations to encourage donors by disclosing accounting information.

\section{CHARITY ORGANIZATIONS' DEVELOPMENT IN CHINA}

The following Table 1 shows the changes in the scale of charitable organizations from 2009 to 2019 based on the statistics of the Green Paper of Chinese charity organizations.

Table 1. The number of various charitable organizations from 2009 to 2019

\begin{tabular}{|l|l|l|l|l|}
\hline $\begin{array}{l}\text { Year } \\
\text { Type }\end{array}$ & $\begin{array}{l}\text { Social } \\
\text { organization/Total } \\
\text { (unit:thousand) }\end{array}$ & $\begin{array}{l}\text { Social group } \\
\text { (unit:thousand) }\end{array}$ & $\begin{array}{l}\text { Private } \\
\text { Non-enterprise } \\
\text { (unit:thousand) }\end{array}$ & $\begin{array}{l}\text { Foundation } \\
\text { (unit:pcs ) }\end{array}$ \\
\hline 2009 & 431 & 239 & 190 & 1843 \\
\hline 2010 & 439 & 243 & 195 & 2168 \\
\hline 2011 & 462 & 255 & 204 & 2613 \\
\hline 2012 & 492 & 268 & 221 & 2961 \\
\hline 2013 & 541 & 286 & 251 & 2961 \\
\hline 2014 & 600 & 307 & 289 & 4044 \\
\hline
\end{tabular}




\begin{tabular}{|l|l|l|l|l|}
\hline 2015 & 658 & 326 & 327 & 4719 \\
\hline 2016 & 699 & 335 & 359 & 5523 \\
\hline 2017 & 762 & 355 & 400 & 6307 \\
\hline 2018 & 816 & 366 & 443 & 7027 \\
\hline 2019 & 867 & 372 & 487 & 7580 \\
\hline
\end{tabular}

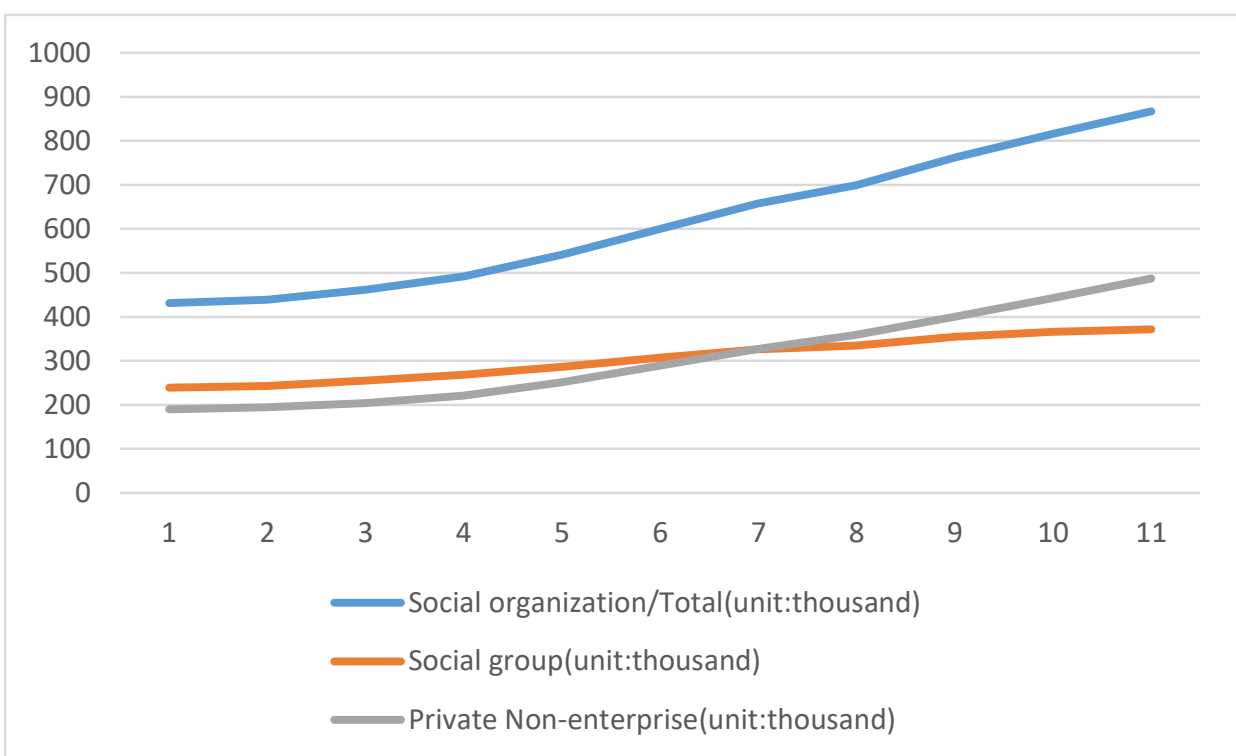

Figure1 Comparison of the number of social organizations from 2009 to 2019

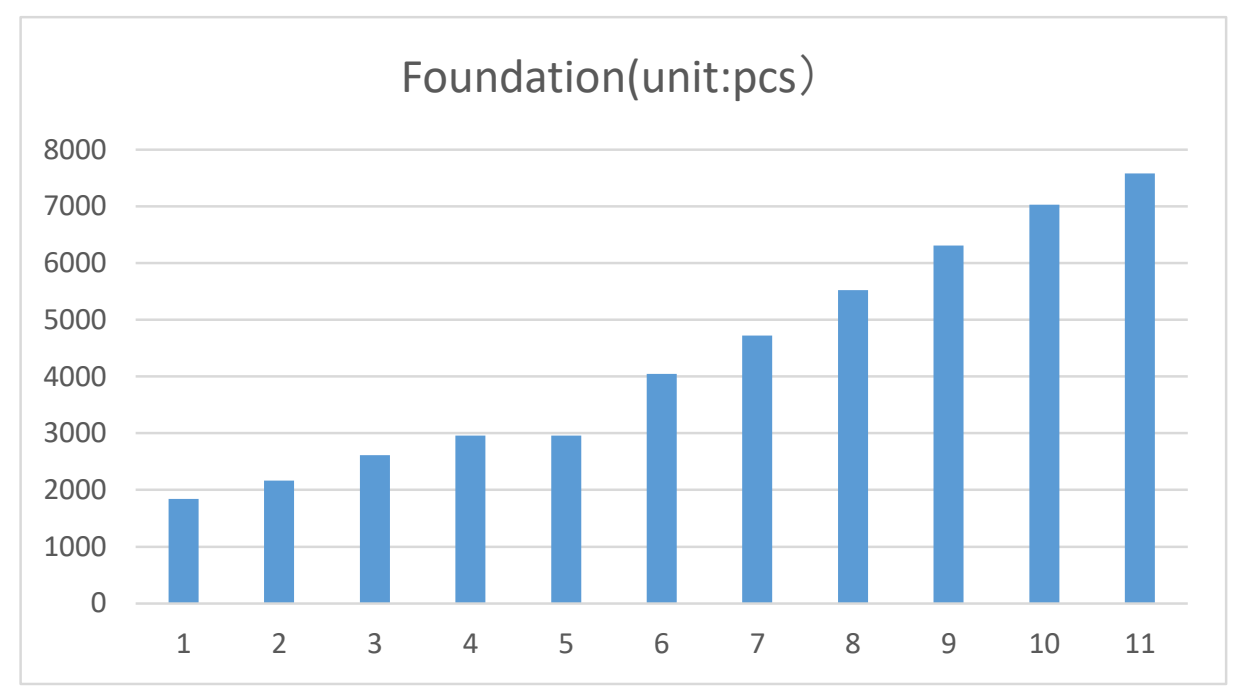

Figure 2 Comparison of the number of foundations from 2009 to 2019

The information that can be obtained from Figure 2 is that the number of charities in China is steadily increasing. At the end of 2019 , there were 867,000 social organizations, including 372,000 social groups, 487 private non-enterprises and 7580 foundations, as can be seen from Figure 1. Social groups, private non-enterprises and foundations developed rapidly. In 2016, the number of private non-enterprises exceeded the number of social groups.

\subsection{Current situation of accounting information disclosure of charity organizations}

FTI is a system invented by the China Foundation Center Network in 2012. It integrated weights, information disclosure channels, completeness and other parameters, and used a ranking list to present the foundation transparent standard evaluation system. According to ANNUAL REPORT ON CHINA'S PHILANTHROPY DEVELOPMENT(2020), since 2015 , the FTI score has been reduced year by year, from 
52.5 to 35.97. Some of the foundation's annual report information was disclosed late or even not disclosed, and less than $10 \%$ of the information was publicly disclosed, which seriously affected the score [4]. In addition, the foundation has developed rapidly in recent years, and the transparent construction of new institutions needs to be improved. This information indicates that the current timeliness and completeness of the foundation information still needs to be strengthened.

\subsection{Problems in the accounting information disclosure}

\subsubsection{Insufficient government supervision}

In recent years, charitable organizations have developed rapidly, but they have not been effectively supervised by the government, which has led to the generation of some negative news and a crisis of trust in charities. The government has established dual supervision of the registration agency and the competent business department, responsible for the registration of charitable organizations and phased supervision and inspection. However, the dual supervision has led to the unclear functions of the two institutions, making the supervision inefficient. In addition to registration and staged supervision and inspection, the government lacks other management tasks such as daily management of charitable organizations. The competent department only pays attention to the specific work of its management, and other parts are blank [5]. As a result, the government needs to pay attention to the actual work management of charitable organizations and set up requirements on the quality of accounting information. In addition, the government also needs to establish a special legal system for the disclosure of accounting information for charitable organizations.

\subsubsection{Accounting system's uniformity}

Among the organizations under the Red Cross system, charitable organizations established by the government apply the Government Accounting System, while other civil organizations apply the Non-profit Organization Accounting System. Due to the different nature of the organizations, the requirements for accounting information in the system are also very different, resulting in no unified accounting system in the industry [6]. In 2019, the Red Cross Society issued relevant documents clearly dividing the applicable institutions of the two systems. However, the current Red Cross system does not clearly distinguish the scope of use of the two systems, nor does it disclose the two sets of statements. Therefore, relevant organizations need to further supervise the implementation of the two systems and strengthen the comparability of accounting information.

\subsubsection{Low awareness of disclosure}

In the current situation, we mentioned that some charitable organizations disclose less than $10 \%$ of the information and the situation was not updated in time. However, the intensity of people's willingness to donate is directly related to the amount of donation. Therefore, charitable organizations should be aware of the importance of financial information to users of financial information such as the public, and charitable organizations should increase their awareness of information disclosure in order to further improve the quality of information.

\subsubsection{Internal organization needs adjustment}

First of all, most charitable organizations lack professional accounting personnel. After raising their awareness of disclosure, charitable organizations should manage to find high-quality accounting personnel for the organization, so as to provide the society with high-quality accounting information. On the other hand, some charitable organizations have not yet established effective internal management systems. Sometimes important decisions are directly made by a small number of people, which directly reduces the operational efficiency of the organization. Sometimes, people in some organizations value personal interests more than the overall interests of the organization, resulting in charitable organizations are under mismanagement.

\section{IMPROVEMENT AND SUGGESTIONS}

\subsection{Establish a unified accounting information disclosure system}

By establishing uniform information disclosure standards, including business activities and fund income and expenditures, it not only clearly reflects the fund operation of charitable organizations, but also reduces the problem of imperfect information disclosure by many organizations. At the same time, it also contributes to the comparability of data, which is conducive to outside supervision of charitable organizations.

\subsection{Strengthen government management}

A standardized and strictly enforced law can effectively supervise charitable organizations. For charitable organizations, they need to make continuous improvement to meet government requirements. Enhancing the accounting information disclosure of charitable organizations will help charitable organizations operate more effectively. On the other hand, the public can see the operation of charitable organizations from the data, which led to an increase in 
the public's willingness to donate. The increasing donation shows affirmation to the work of charitable organizations. As a result, the charitable organizations and public will form a good cycle. In addition, the government should require charitable organizations to submit audit reports to ensure the authenticity of the data. The government should encourage charitable organizations to hire professional accounting firms to conduct independent audits of data. Regulatory authorities should conduct random checks and audits of charitable organizations' financial data on a regular and irregular basis. In addition, social media need to improve new's immediacy and expand broad audiences in order to further improved the quality of accounting information disclosure [7].

\subsection{Improve social disclosure awareness}

People's donations are the main source of income for charitable organizations. By publicizing the approaches that public can participate in public welfare undertakings, more people can participate in philanthropy, causing philanthropy can play a role in more fields. At the same time, the public should understand the role of financial information statements and pay more attention to charitable financial information. As a result, charitable organizations need to allow the public to access the organization's financial information, which protects the rights of the public [8].

\section{CONCLUSION}

Charity organizations have played an important role in many events in society. However, many charity scandals have led to a decline in people's trust in charity organizations and slowed down the development of charity organizations. The accounting report of charity organizations is an important manifestation of the credibility of charity organizations. The main conclusions drawn in this article are as follows: First, because of the public product theory, information asymmetry theory and principal-agent theory, there is a imbalance of information between donors and organizations. Accounting information disclosure is the main way for people to understand the operation of a charity. Second, with the rapid development of charitable organizations in my country, there are many shortcomings in accounting information disclosure, including insufficient government supervision, inconsistent accounting systems, lack of awareness of disclosure, and adjustments to internal organizations. Lastly, this paper puts forward three suggestions that can promote accounting information: establish a unified accounting information disclosure system, strengthen government management and improve social disclosure awareness. This paper still has many deficiencies in the research on accounting information disclosure of charitable organizations. For example, it did not specifically discuss a unified accounting disclosure system, and did not consider other factors that may affect the amount of social donations. Therefore, this paper has certain limitations and needs to be further improved in the future research.

\section{ACKNOWLEDGMENT}

Many thanks to Professor Sun, Miss Wang and Miss Liu for offering the guidance and help in writing this paper, during this process I learned a lot about accounting statements and completed this paper. I am also very grateful to the authors of relevant literature in the field of philanthropy accounting, their academic researches inspired me a lot.

\section{REFERENCES}

[1] Yuan Pengcheng, Study of Nonprofit Organization's Financial Governance and Financial Information Disclosure Status-Based on Questionnaire Survey in Shanghai [D] East China University of Science and Technology, 2014, p15-16.

[2] Cai Yixuan, The Research on Financial Governance of Non-profit Organizations [D] Anhui University of Finance and Economics, 2011, p11-13.

[3] Liu Xiaonan, Research on Information Transparency of Non-Profit Organizations under Entrusted Agency: Based on the Status Quo of Charitable Fund Organizations [J] Commercial Accounting, 2012(2), p59-60.

[4] Cheng Gang \& Wang Lu \& Huo Da, 2019 China Foundation Development Report, 2020.

https://www.pishu.com.cn/skwx_ps/databasedetail ?SiteID=14\&contentId=11978920\&contentType $=1 \mathrm{i}$ terature \&type $=\% 25 \mathrm{E} 6 \% 258 \mathrm{~A} \% 25 \mathrm{~A} 5 \% 25 \mathrm{E} 5 \% 259$ $1 \% 258$ A\&subLibID $=$

[5] Lu Beibei, Study on the Government Supervision of Charity Organization in China [D] Jiangxi University of Finance and Economics, 2012, p18-21.

[6] Gao Xinhui. Research on Charity Accounting Information Disclosure [D] Shenyang University, 2017, p27.

[7] Wang Zhen. Research on Private Non-profit Organization's Financial Information Disclosure Issue [D] Chang'an University, 2015, p46.

[8] Jiang Xuyan, Research 011 Problems of Chinese Charity Accounting and Information Disclosure [D] Shenyang University, 2014, p44. 